\title{
Modeling and Simulation of Nanofluid Minimum Quantity Lubrication Surface Grinding Thermal Stress
}

\author{
Yanbin Zhang, Changhe Li ${ }^{*}$, Min Yang, Dongzhou Jia, Dongkun Zhang and Xiaowei Zhang
}

School of Mechanical Engineering, Qingdao Technological University, 266033, China

\begin{abstract}
The model of surface grinding with a nanoparticle jet flow of MQL was established. The surface grinding thermal stress of three workpiece materials, namely, $45 \mathrm{Steel}, 2 \mathrm{Cr} 13$, and nano- $\mathrm{ZrO}_{2}$ dental ceramic, were numerically simulated. Results show that dry grinding generates larger tensile stress, whereas MQL grinding generates larger compressive stress. The finished surface of workpiece produces large tensile stress in grinding direction. With the increase of cutting depth, the time-related variation of thermal stress on finished surface slows down gradually. Residual stress is inversely proportional to cutting depth. With the increase of cutting depth, the finished surface of workpiece is firstly dominated by large tensile stress, which decreases continuously until reaching the maximum compressive stress. Deeper layer is less influenced by temperature field, manifested by smaller stress value and slight variation of the whole stress field.
\end{abstract}

Keywords: Cooling performance, grinding zone temperature, minimum quantity lubrication (MQL), nano-particles, jet flow, thermal stress, lubricating properties, tribological features.

\section{INTRODUCTION}

In machining, in order to obtain precise surface tolerances and clean part surface, the grinding is an inevitable procedure. In the manufacturing of industrialized countries, grinding costs account for $20 \%-25 \%$ of the machining costs, and grinding is of great importance. Grinding wheel is contacted with the workpiece and removes workpiece materials by sliding and plowing $[1,2]$. In this process, a lot of energy will be consumed to remove the material per unit of volume. The energy is then transformed into heat that concentrates on the grinding zone. Heat accumulation then forms a high-temperature condition, leading to thermal injury of workpiece, such as burns, cracks, metallurgical changes etc. It will also lead to workpiece deformation and other consequences. In order to reduce the temperature in the grinding zone, people have considered using liquid for temperature reduction. To this end, the flood cooling technique is applied in the grinding. As the grinding fluid can function in lubricating, cooling and washing, the grinding fluid can be casted in the grinding zone to reduce temperature. In the processing, the grinding fluid also removes debris. Compared with abrasive grinding, flood grinding can improve surface quality of workpiece [3, 4]. The grinding fluid cools the workpiece by heat convection, which reduces the grinding temperature of workpiece. For flood cooling, a mass flow of the grinding fluid is used to cast the wedge-shaped area between grinding wheel and the workpiece. Due to the air bond formed from the high-speed revolution of grinding wheel and other

*Address correspondence to this author at the School of Mechanical Engineering, Qingdao Technological University, 266033, China; Tel: +86-532-85071757; Fax: +86-532-85071286;

E-mail: sy_lichanghe@163.com factors, a great amount of the grinding fluid is hard to enter the interface of grinding wheel and workpiece. In fact, the effective flow rate entering the interface is only $5 \%-40 \%$. Thus, massive grinding fluid supplies leak out during the grinding. Due to the low effective utilization rate of the grinding fluid, wasted grinding fluid should be recycled and processed. The expenses on purchasing and processing the grinding fluid take up a high proportion in the total costs of machining. Liquid waste disposal also requires enormous costs, reaching up to $54 \%$ of all costs of the grinding fluid [5-7]. In the processing, the grinding fluid may be volatilized, leaked out or spilled in the vaporific form, causing environmental deterioration of the working places, land and water contamination, and destroying the ecological environment. If the volatilized grinding fluid under heat directly contacts human body, it will treat the health of operators, triggering a range of skin, respiratory tract, and lung diseases. In order to protect the environment and reducing costs, people choose to use the abrasive grinding without the grinding fluid, showing prominent advantages in terms of ecology. As the grinding consumes more energy by removing per unit material than other types of processing, a mass of heat is accumulated in the grinding zone $[8,9]$. Only $10 \%$ of the heats are carried away by abrasive dusts during the grinding, and the rest is accumulated to form a hightemperature zone. Without the lubricating and cooling effects of the grinding fluid, the grinding wheel will be seriously worn, and the workpiece precision and the surface integrity will be degraded. People used to try to replace the grinding fluid by solid lubricants. Although solid lubricants can perform certain lubricating effects, when solid lubricant enters the surface pores of grinding wheel, the grinding wheel will lose the grinding performance [10-12]. It also leads to increasing grinding force and degrading surface quality of workpiece. 
Therefore, a new cooling and lubrication technology, the Minimum Quantity Lubrication (MQL) cooling between dry processing and flood cooling was invented. Baheti [12] proposed Minimal Quantity Lubrication (MQL) technology. MQL grinding is to mix a minimum quantity of lubricant in the high-pressure air, which then injects the pulverized mixture in the high-temperature grinding zone. The lubricating fluid adheres on the machined surface of workpiece, forming a protective film and functioning as a lubricant. MQL combines advantages of flood grinding and dry grinding, and its lubrication effects are barely different with traditional flood grinding. The scholars also explored into the proper amount of the grinding liquid. Under the premise of meeting the processing needs, they also studied the concentration of the grinding liquid, the workpiece material, tool parameters and other parameters. Besides, the effects of MQL on surface roughness, cutting force, built-up edge and other aspects were analyzed. Based on findings of experiments and research, the optimal usage of the grinding liquid was observed. Subsequently, MQL has been widely used in machining like drilling, cutting and milling. The grinding effects have been greatly improved but setbacks still exist. Compared with dry processing, the usage of grinding liquid in MQL is reduced, and over $20 \%$ of energy is saved. It reduces over $15 \%$ of grinding costs and extends the service life of tools for over a doubled time. Besides, the surface quality and the processing efficiency are greatly improved [13-15]. Given that the grinding produces a great amount of energy at the interface of grinding wheel/workpiece when removing per unit volume of material, it is more challenging to introduce $\mathrm{MQL}$ technology with less efficient cooling performance in the grinding than other processing methods. So far, only a few research teams carried out exploratory studies on MQL grinding technology. Baheti and others probed into the prospects of using MQL in the grinding from the perspectives of environmental and ecological protection. Research demonstrated that compared with traditional flood grinding, the usage costs of the grinding fluid in MQL grinding was reduced by $65 \%$ and the equipment investment was reduced by $22 \%$ [12-20]. Besides, the naturally biodegradable synthetic ester is used as lubricant, which minimizes the hazards of the grinding fluid to environment and human body. Silva et al. studied on surface integrity, specific grinding energy and grinding wheel wearing comparison of workpiece under different processing modes, like abrasive grinding, flood grinding and MQL. Results showed that compared with flood grinding, MQL provided effective lubrication but the cooling effects were less efficient and the surface integrity of the workpiece was degraded. Tawakoli and others [21-23] studied the effects of grinding parameters on surface quality of workpiece in the experiment at the flat grinder. Compared with flood grinding, with the optimization of grinding parameters and grinding fluid parameters, the surface quality of workpiece was improved while tangential grinding force and specific grinding energy decreased. Barczak and others [24-26] used precision surface grinding machine to compare and analyze grinding power, grinding force, grinding temperature and surface roughness among MQL grinding, flood grinding and dry grinding. Results showed that at a proper specific material removal rate, grinding force and grinding power of
MQL grinding overweigh that of flood grinding. However, its surface roughness of workpiece and residual stress were not as good as flood grinding. Prof. Wang [27] also conducted the grinding contrast test on precision numerical control grinder, comparing the cutting fluids of minimum oils on water and emulsified liquid, soluble solution, and minimum quantity water spray and oil spray grinding fluid with the minimum cutting depth $(5 \mu \mathrm{m})$. Besides, they identified the grinding force, surface roughness, temperature in the grinding zone and grinding ratio. The research showed that cooling performance of the cutting fluids of minimum oils on was poorer than traditional fluids like emulsified liquid and soluble solution, but it showed excellent lubricating performance, and prominent advantages in terms of increasing grinding precision and the service life of grinding wheel. However, due to the limited heat exchange capability of minimum water drops, this approach is only suitable for grinding conditions with low grinding energy. Compared with flood grinding, grinding with minimum quantity lubricant reduces the service life of grinding wheel and processing quality of workpiece. Burns are also found on the workpiece surface. Research presented that cooling effects of high-temperature air flow are limited, which could not meet the needs of heat transfer enhancement at high temperature in the grinding zone. Besides, this method greatly reduced the grinding quality of workpiece and the service life of grinding wheel, indicating that MQL technology needs further improvement [18-20]. According to the theory of heat transfer enhancement, the thermal conductivity of solid is greater than liquid, and the thermal conductivity of liquid is greater than gas. Over the globe, researchers [28-37] have proposed a way to improve the insufficient heat exchange of MQL by adding solid nanoparticles in the grinding fluid. Shen and others [28, 29] studied on the grinding performance by adding $\mathrm{MoS}_{2}$ nanoparticles in the MQL grinding fluid, and their findings presented that the lubricating property and high-thermal conductivity of nano-particles greatly improved the service life of workpiece surface quality and grinding wheel. They also conducted comparative research on grinding performance of nano-particles by adding $\mathrm{Al}_{2} \mathrm{O}_{3}$ in the MQL grinding fluid or other nano-particles, and under the condition of using different concentrations of nano-particles. Kalita and others [38] conducted experiments on the impacts of different grinding fluids on grinding performance by adding $\mathrm{MoS}_{2}$ nano-particles in the MQL grinding fluid. The research team from Qingdao Technological University conducted further and systematic research on the technology and equipments of nano-particles jet MQL grinding. $\mathrm{Gu}$ [39] also explored into the applicability of MQL grinding, and discussed the influencing patterns of processing parameters on surface quality. Shang [40] also carried out an experiment on the high-speed grinding MQL jet parameters. Results showed that the position of nozzle influenced the high-speed MQL grinding in a most significant way. Liu [41] studied the heat transfer mechanism of flat surface grinding with nano-particles jet MQL and evaluated the surface integrity, and they also experimented on the grinding temperature field. Results showed that the grinding depth was the most important influencing factor of temperature in the grinding zone. Han [42] carried out the theoretical modeling and experiences on the flow field of the grinding zone with nano- 
particles jet MQL, including the jet parameters, influencing patterns of processing parameters on the velocity field and pressure field of the grinding zone. Li [43] also researched on the modeling and numerical simulation of nano-particles jet MQL grinding temperature field, established the heat transfer model of flat grinding temperature field with nanoparticles jet MQL, and the proportionality coefficient model of energy injecting into the workpiece. The researcher carried out the numerical simulation and experimental study of surface grinding temperature field with three workpieces, namely, 45 steel, $2 \mathrm{Cr} 13$ and nano-zirconia ceramics.

Although researchers home and abroad have accomplished profound and systematic studies on MQL, especially on nano-particles jet MQL. It can solve the shortage of MQL in cooling performance, greatly improve the working environment, save energy and reduce costs to achieve a low-carbon manufacturing. The unique lubricating performance and tribological property of solid nano-particles form nano-particle shearing films at the grinding wheel/workpiece interface, which can enhance the lubricating performance of MQL grinding [44-53]. Existing studies on MQL grinding equipments, however, cannot meet the needs of the technological development. During surface grinding, the friction and extrusion of workpiece under the quick revolution of grinding wheel will produce instant hightemperature with great non-uniform distributed temperature gradients, which finally results in the thermal stress. Thermal stress can affect the service quality, dimensional stability, fatigue strength, abrasive resistance, corrosion resistance and fatigue cracks of workpiece significantly. In this paper, modeling and finite element simulation of nanofluid minimum quantity lubrication (MQL) surface grinding thermal stress were implemented and the effect of grinding thermal stress under different cooling lubrications was discussed.

\section{GENERATION OF RESIDUAL STRESS}

Residual stress after grinding pertains to elastic-plastic mechanics when viewed from its generation mechanism. During surface grinding, residual stress is mainly caused by grinding heat and grinding thermal stress on the finished surface of workpiece as well as elasticoplastic deformation of the workpiece. The value and distribution of residual stress are determined by these three causes together. The distribution of residual stress is shown in Fig. (1).

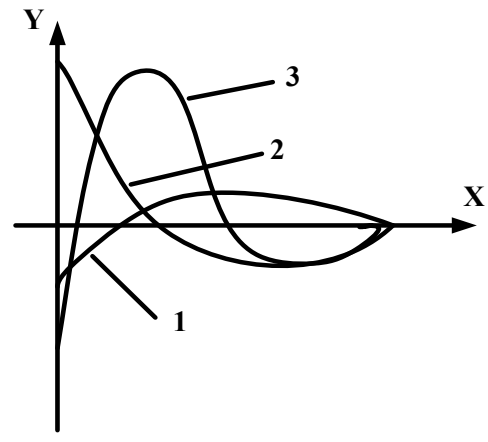

1. grinding force 2. grinding heat 3 . phase transition $\mathrm{x}$-depth $\mathrm{y}$-residual stress

Fig. (1). Residual stress distribution on finished surface of workpiece.
As for fracture removal in the middle and late grinding process, it should give the consideration to the model of indentation fracture mechanics [54-56]. The modeling of indentation fracture mechanics was based on the approximate small-range indentation on abrasive particles and workpiece surface in ceramics grinding. It generally includes fixed and mobile indenter models. Fig. (2) shows a fixed indenter model. Right under the indenter, there is a small plastic deformation area. From this area, two major fracture systems are formed, namely, radial crack and transverse crack. Generally, radial crack will reduce the material strength, even microscopic damages on the surface or sub-surface. Meanwhile, transverse crack mainly leads to the removal of materials and influences the surface roughness after the processing.

In Fig. (1), Curve 1 represents residual stress on workpiece caused by grinding force during surface grinding. During the grinding process, the high-speed relative motion between finished surface of workpiece and grinding wheel will produce great plastic deformation, causing residual stress. It can be seen from Fig. (1) that the residual stress on finished surface of workpiece caused by grinding force is residual compressive stress. Curve 2 represents residual stress caused by grinding heat. It is a residual tensile stress caused when the grinding heat-induced deformation exceeds the elastic deformation range. Curve 3 represents the phase transition caused by grinding heat after the workpiece temperature reached to certain critical temperature. The property of residual stress caused by phase transition (residual compressive stress or residual tensile stress) is mainly determined by grinding temperature and physical properties of the workpiece material.

Based on a lot of experimental studies, $\mathrm{C}$ proposed a formula to determine whether there's residual tensile stress on grinding surface.

$$
\begin{aligned}
& \sigma(z)=\sigma_{\text {yield }}(T),\left(-\frac{1}{2} d \leq z \leq z_{y}\right) \\
& \sigma(z)=\frac{1}{1-v}\left[-E \alpha T+\frac{1}{d} \int_{-\frac{d}{2}}^{\frac{d}{2}} E \alpha T d z+\frac{12 z}{d^{3}} \int_{-\frac{d}{2}}^{\frac{d}{2}} E \alpha T z d z\right], \\
& \left(z_{y} \leq z \leq \frac{d}{2}\right)
\end{aligned}
$$

where $\sigma_{\text {yield }}$ is the yield stress of workpiece material (Mpa), $\mathrm{T}$ is the maximum temperature on grinding surface $\left({ }^{\circ} \mathrm{C}\right), v$ is the Poisson's ratio of workpiece material, $\alpha$ is the coefficient of thermal expansion of workpiece material (Gpa), $\mathrm{d}$ is thickness of workpiece $(\mathrm{mm})$, and $z_{y}$ is the cutting depth at yield stress limit of workpiece material $(\mu m)$.

According to (1) and (2), higher grinding temperature causes higher thermal stress on finished surface of workpiece correspondingly. When the maximum thermal stress is smaller than the yield stress of workpiece material, no residual stress will be developed after grinding. However, when the maximum thermal stress exceeds the yield stress of workpiece material, the thermal effect will cause residual stress on workpiece. (1) and (2) can only contribute approximate calculation and analysis because $\mathrm{T}$ is a variable 
of one-dimensional thermal conduction. To gain accurate calculation and analysis, $\mathrm{M}$ et al. improved them.

$\sigma(x, y, z)=\sigma_{\text {yield }}(T),\left(-\frac{d}{2} \leq z \leq z_{y}\right)$

$\sigma(x, y, z)=\sigma(x, y, z, T),\left(\mathrm{z}_{\mathrm{y}} \leq z \leq \frac{d}{2}\right)$

where $\sigma(x, y, z)$ is the stress sum at any point and $\sigma(x, y, z, T)$ is the stress sum under different temperatures.

(3) and (4) calculate the grinding thermal stress by using finite element method, which is used to predict the generation of residual stress.

\section{THEORETICAL MODEL OF SURFACING GRINDING THERMAL STRESS}

The linear strain of workpiece material during surface grinding is $\alpha\left(\varphi-\varphi_{0}\right)$ ( $\alpha$ is the coefficient of linear expansion of workpiece material; $\varphi_{0}$ is initial temperature; and $\varphi$ is the instant temperature). Distributions of the whole temperature field $(\varphi)$ and thermal stresses on finished surface of workpiece can be analyzed by taking node temperature as the variable value. The constitutive relation of workpiece material during thermal stress calculation can be expressed by:

$\varepsilon_{x}=\frac{1}{E}\left[\sigma_{x}-\mu\left(\sigma_{y}+\sigma_{z}\right)\right]+\alpha T, \gamma_{x y}=\frac{1}{G} \tau_{x y}$

$\varepsilon_{y}=\frac{1}{E}\left[\sigma_{y}-\mu\left(\sigma_{x}+\sigma_{z}\right)\right]+\alpha T, \gamma_{y z}=\frac{1}{G} \tau_{y z} \Rightarrow$

$\sigma_{i j}=D_{i j k l}\left(\varepsilon_{k l}+\varepsilon_{k l}^{0}\right)$

$\varepsilon_{z}=\frac{1}{E}\left[\sigma_{z}-\mu\left(\sigma_{x}+\sigma_{y}\right)\right]+\alpha T, \gamma_{z x}=\frac{1}{G} \tau_{z x}$

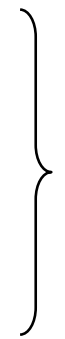

where $\varepsilon_{k l}^{0}=\left[\begin{array}{llllll}\alpha \Delta T & \alpha \Delta T & \alpha \Delta T & 0 & 0 & 0\end{array}\right]^{T}$.

Implement finite element discretization to (5). The displacement array of a cell node is:

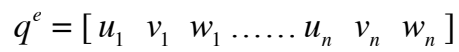

Substitute mechanical parameters in (6) with nodal displacement functions:

$u=N q^{e}, \varepsilon=B q^{e}$

$\sigma=D\left(\varepsilon-\varepsilon^{0}\right)=D B q^{e}-D \varepsilon^{0}=S q^{e}-D \cdot \alpha_{T} \Delta T\left[\begin{array}{lllll}1 & 1 & 1 & 0 & 0\end{array}\right]^{T}$

where $\mathrm{N}$ is element property functional matrix, $\mathrm{B}$ is geometric matrix, $\mathrm{D}$ is elastic coefficient matrix and $\mathrm{S}$ is stress matrix.

Calculate the element displacement as well as virtual displacement and virtual strain of strain

$\left.\begin{array}{l}\delta u=N \cdot \delta q^{e} \\ \delta \varepsilon=B \cdot \delta q^{e}\end{array}\right\}$
Substitute (9) into the expression of principle of virtual displacement:

$\int_{\Omega} D_{i j k l} \varepsilon_{k l} \delta d \Omega-\left(\int_{\Omega} \overline{b_{1}} \delta u_{1} d \Omega+\int_{\Omega} \overline{p_{1}} \delta u_{1} d A+\int_{\Omega} D_{i j k l} \varepsilon_{k l}^{0} \delta \varepsilon_{i j} d \Omega\right)=0$

Eliminate the randomness variable $\left(\varepsilon q^{e}\right)$, then,

$K^{e} q^{e}=P^{e}+P_{0}^{e}$

where $\quad K^{e}=\int_{\Omega^{\prime}} B^{T} D B d \Omega \quad$ (structural stiffness matrix), $P^{e}=\int_{\Omega^{\prime}} N^{T} \bar{b} d \Omega+\int_{\Omega^{\prime}} N^{T} \bar{p} d A$ (equivalent load item, MPa) and $P_{0}^{e}=\int_{\Omega^{\prime}} B^{T} D \varepsilon^{0} d \Omega$ (temperature equivalent load item, MPa).

\section{FINITE ELEMENT SIMULATION RESULTS OF SURFACE GRINDING THERMAL STRESS}

Take 45-steel workpiece for example. The variation law of the principal stress at different cutting depths in the grinding direction (X-axis) was shown in Fig. (2).

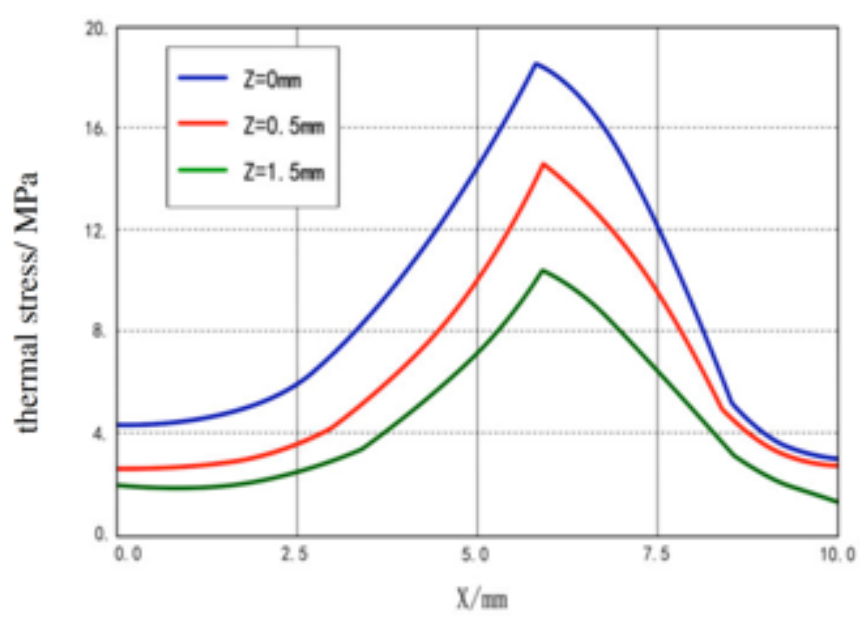

Fig. (2). Variation law of the principal stress at different cutting depths.

Fig. (2) presents three variation curves of the principal stress at three cutting depths in the grinding direction ( $\mathrm{x}-$ axis). Grinding process produces great thermal tensile stress. The maximum principal stress lies on the grinding surface. The principal stress decreases at a quick speed with the increasing of cutting depth. This variation law agrees with the variation law of temperature field. This is because the finished surface of workpiece will achieve the maximum energy density during grinding. Higher grinding temperature will cause greater temperature gradient and larger thermal stress, thus affecting the grinding surface more significantly.

To explore the distribution law of grinding thermal stress systematically, a finite element analysis was carried out based on 45-steel, $2 \mathrm{Cr} 13$ and ceramics. The variation laws of grinding thermal stress on the surface of these three materials were presented in Figs. (3-5).

According to Figs. (3-5), under high grinding temperature, all of these three materials showed evident 
thermal expansion on surface and uneven plastic deformations due to the substrate constraint. Additionally, grinding heat effect on the grinding region presented instantaneous thermal pulse.

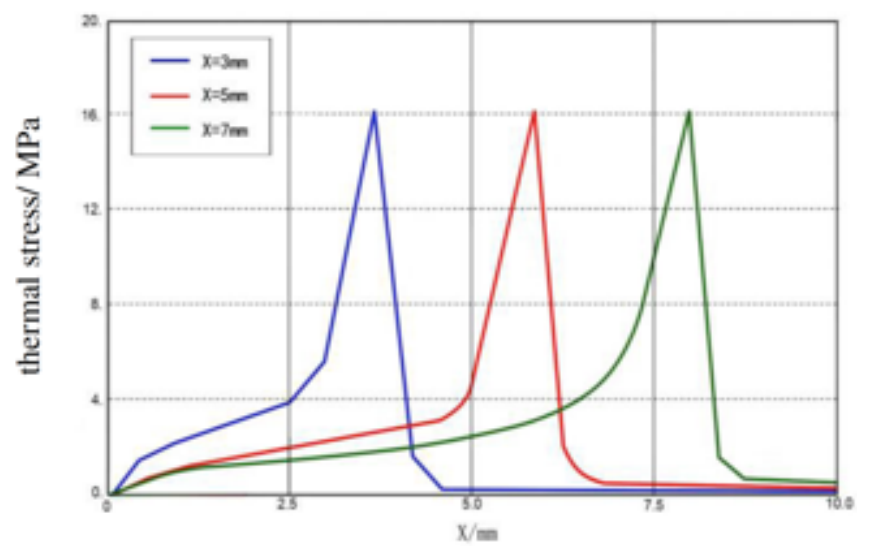

Fig. (3). Thermal stress distribution on 45 -steel surface.

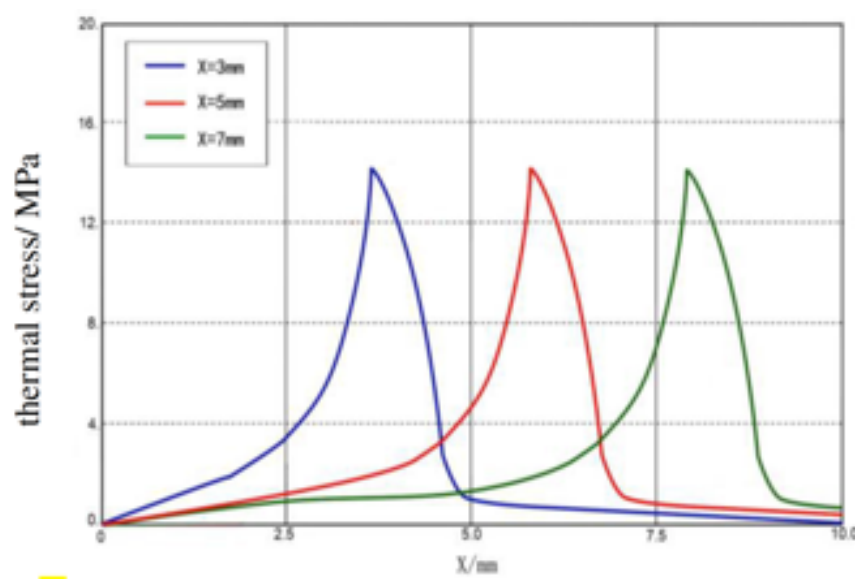

Fig. (4). Thermal stress distribution on $2 \mathrm{Cr} 13$ surface.

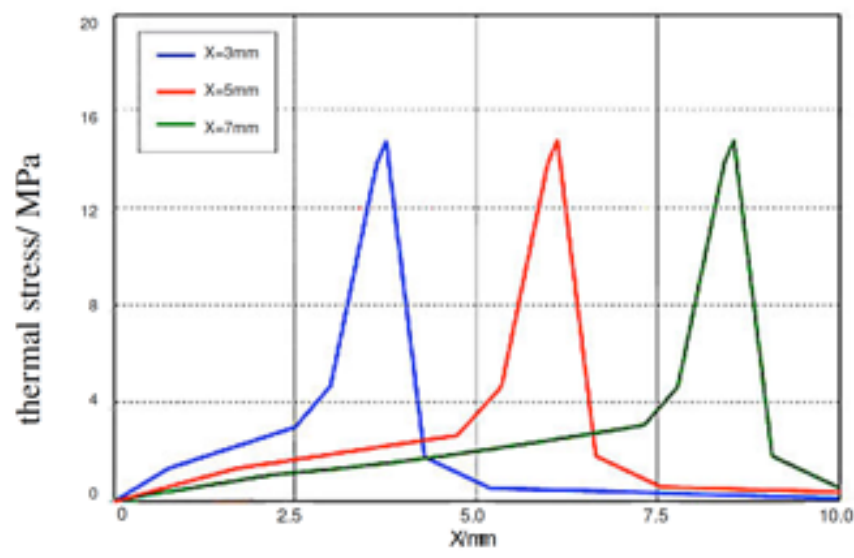

Fig. (5). Thermal stress distribution on ceramics surface.

The variation laws of thermal stress of three test materials with the increase of cutting depth were compared (Fig. 6). Three test materials have similar variation law of equivalent stress. The residual tensile stress caused by thermal stress drops quickly with the increase of cutting depth until turn into residual compressive stress. With the continuous deepening of cutting process, this residual compressive stress will turn into residual tensile stress again after reaching the maximum residual compressive stress.
Due to the different physical properties of three test material, time for temperature-induced property change from nature state to plastic state and then to elastic-plastic state as well as heat exchange capability during cooling differs from each other, thus resulting in different their different thermal stress values.

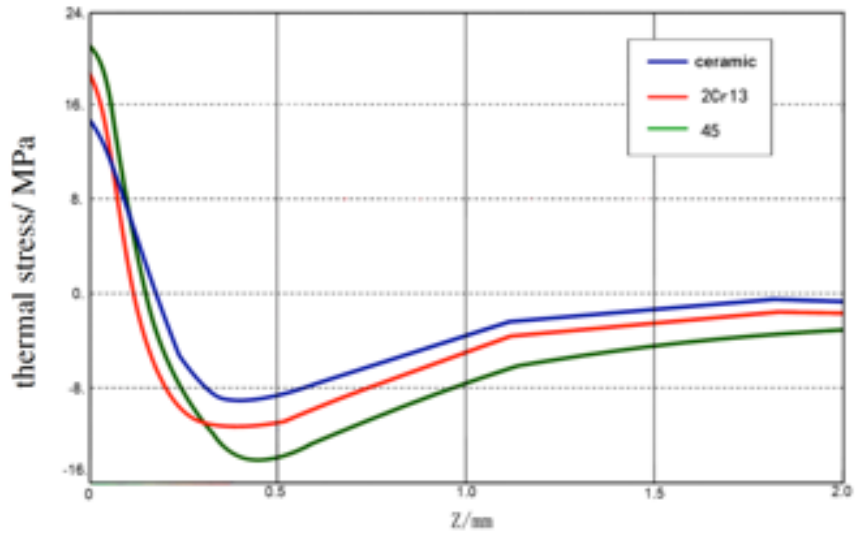

Fig. (6). Thermal stress variation of three test materials with cutting depth.

Fig. (7) shows the variation law of thermal stress on finished surface of 45-steel workpiece in grinding direction (X-axis). Great stress gradient is observed in Fig. (7). The stress value and stress gradient under dry grinding are significantly larger than that under MQL grinding. This is because compared to MQL grinding, dry grinding without cooling lubrication medium has higher specific volume and quick deformation of workpiece caused by phase transition (internal microstructure change) under higher grinding temperature and higher heat accumulation on grinding surface.

Fig. (8) shows the cutting depth-related variation law of thermal stress of four cooling lubrication grinding processes at $\mathrm{x}=5 \mathrm{~mm}$. Under dry grinding, finished surface of workpiece is mainly dominated by tensile stress (about 20 MPa at peak) at the beginning due to the high temperature. However, this tensile stress weakens continuously with the feeding of workpiece until reaching the maximum compressive stress $(10 \mathrm{MPa})$ at $0.4 \mathrm{~mm}$. This is because during the grinding, temperature on finished surface of workpiece increases with the continuous feeding of grinding wheel, which causes quick expansion of metallographic structure at the surface layer. Since temperature inside the workpiece remains relative lower, a great temperature gradient is developed at deep layer and the thermal expansion on finished surface of workpiece is restricted by deep cold metal. Consequently, compressive stress is developed inside the workpiece.

The variation law of thermal stress on finished surface of workpiece with grinding width under four cooling lubrication grinding processes is presented in Fig. (9). Thermal stress changes slightly within the grinding width range, but presents great stress gradients at the boundary of outside grinding region and non-grinding region. The distribution law of thermal stress is similar with that of temperature field, indicating that the distribution law of grinding thermal stress in grinding direction is determined by temperature distribution. 


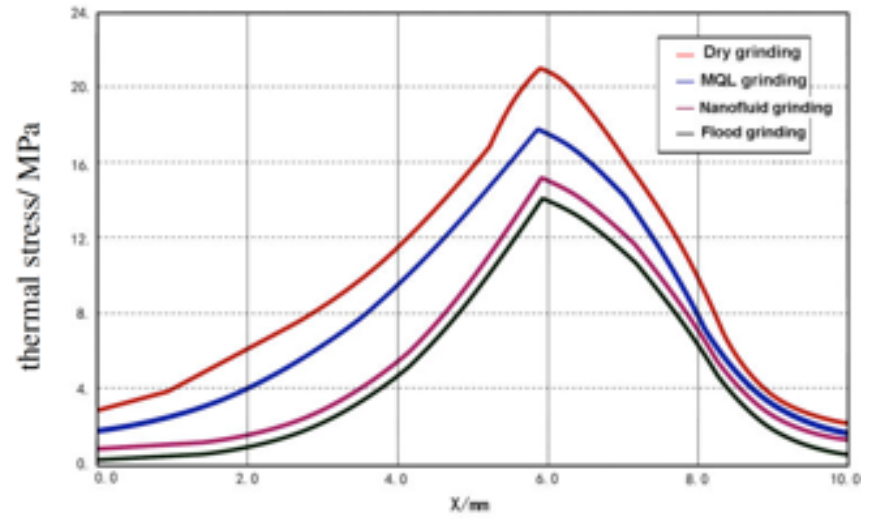

Fig. (7). Variation law of thermal stress in grinding direction.

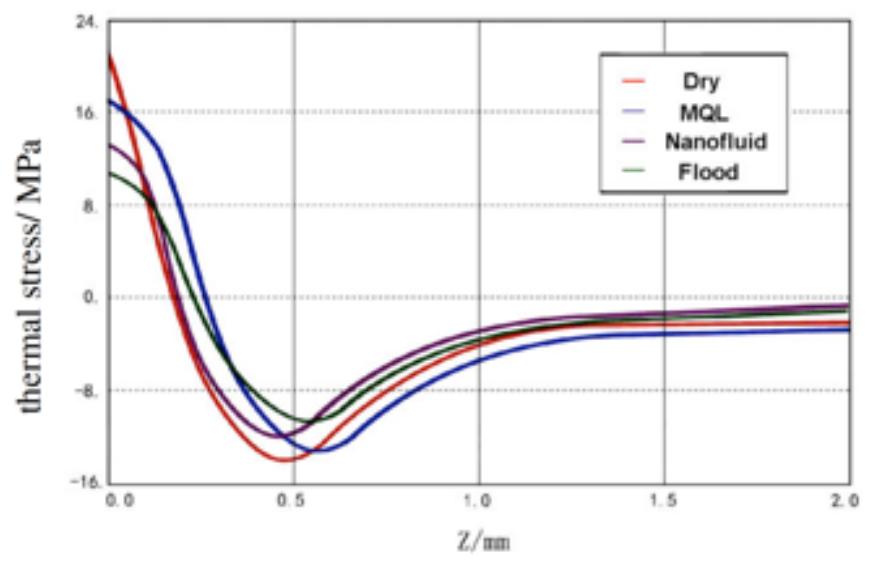

Fig. (8). Thermal stress distribution law at different cutting depth.

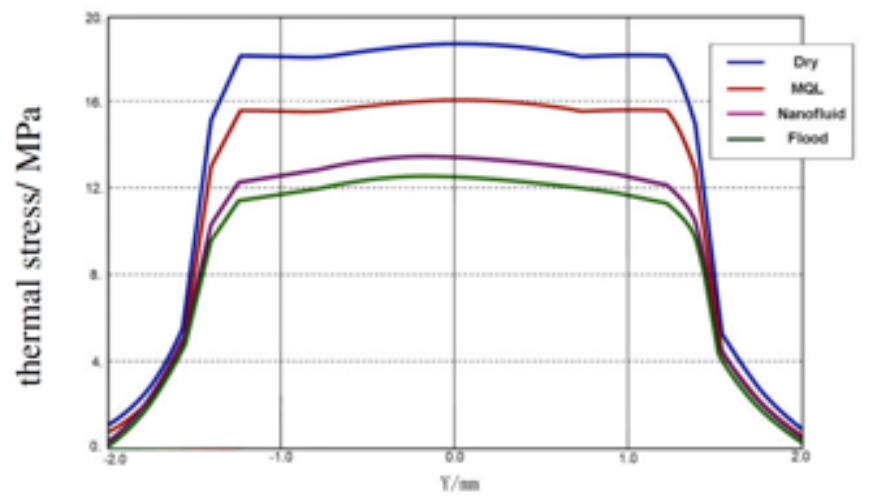

Fig. (9). Thermal stress distribution in y direction.

A proportion relationship between thermal stress and temperature can be observed in Fig. (10). This is because thermal stress is mainly caused by the restricting effect of deep cold metal on the grinding temperature-induced thermal expansion of surface metallographic structure of workpiece.

\section{CONCLUSION}

This paper carries out a finite element analysis on the thermal stress on 45-steel, $2 \mathrm{Cr} 13$ and ceramics during surfacing grinding. The generation mechanism of residual stress is analyzed and a mathematical model of surface grinding thermal stress is established. The time-related variation law of thermal stress on 45-steel, $2 \mathrm{Cr} 13$ and ceramics is discussed through a finite element analysis.
Dry grinding generates larger tensile stress, whereas MQL grinding generates larger compressive stress. The finished surface of workpiece produces large tensile stress in grinding direction. With the increase of cutting depth, the time-related variation of thermal stress on finished surface slows down gradually. Residual stress is inversely proportional to cutting depth. With the increase of cutting depth, the finished surface of workpiece is firstly dominated by large tensile stress, which decreases continuously until reaching the maximum compressive stress. Deeper layer is less influenced by temperature field, manifested by smaller stress value and slight variation of the whole stress field.

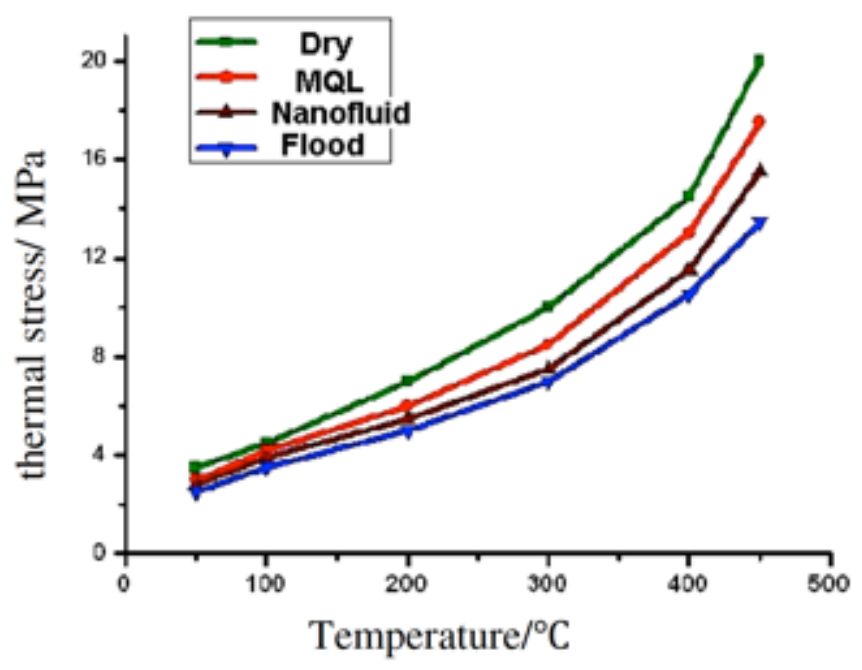

Fig. (10). Temperature-stress variation law.

\section{CONFLICT OF INTEREST}

The authors hereby confirm that no conflict of interest exists for this article.

\section{ACKNOWLEDGEMENTS}

This research was financially supported by the National Natural Science Foundation of China (51175276), the Qingdao Science and Technology Program of Basic Research Projects (14-2-4-18-jch), and the Huangdao District Application Science and Technology Project (2014$1-55)$.

\section{REFERENCES}

[1] J. Kopa, and P. Krajnik, "High-performance grinding-a review", Journal of Materials Processing Technology, vol. 175, no. 1-3, pp. 278-284, 2006

[2] T. Jin, and G.Q. Cai, "Analytical thermal models of oblique moving heat source plane for deep grinding and cutting", Journal of Manufacturing Science and Engineering, vol. 123, no. 1, pp. 185-90, 2001.

[3] S. Malkin, and C. Guo, "Thermal analysis of grinding", CIRP Annals - Manufacturing Technology, vol. 56, no. 2, pp. 760-782, 2007.

[4] E. Brinksmeier, J. C. Aurich, E. Govekar, C. Heinzel, H.-W. Hoffmeister, F. Klocke, J. Peters, R. Rentsch, D. J. Stephenson, E. Uhlmann, K. Weinert, and M. Wittmann, "Advances in modeling and simulation of grinding processes", CIRP Annals Manufacturing Technology, vol. 55, no. 2, pp. 667-697, 2006.

[5] S. Ebbrell, N. H. Woolley, Y. D. Tridimas, D. R. Allanson, and W. B. Rowe, "The effects of cutting fluid application methods on the 
grinding process", International Journal of Machine Tools and Manufacture, vol. 40, no. 2, pp. 209-223, 2000.

[6] C. Frank, Z. Wojciech, and F. Edwin, "Fluid performance study for groove grinding a nickel-based superalloy using electroplated cubic boron nitride (CBN) grinding wheels", Journal of Manufacturing Science and Engineering, vol. 126, no. 3, pp. 451-458, 2004.

[7] Y. Gao, S. Tse, and H. Mak, "An active coolant cooling system for applications in surface grinding", Applied Thermal Engineering, vol. 23 , no. 5, pp. 523-537, 2003.

[8] V. Gviniashvili, J. Webster, and B. Rowe, "Fluid flow and pressure in the grinding wheel-workpiece interface", Transactions of the ASME, vol. 127, no. 1, pp. 198-205, 2005.

[9] M. N. Morgan, A. R. Jackson, and H. Wu, "Optimisation of fluid application in grinding", CIRP Annals-Manufacturing Technology, vol. 57 , no. 1 , pp. 363-366, 2008.

[10] K. Donaldson, X. Y. Li, and W. MacNee, "Ultrafine (nanometer) particle mediated lung injury", J Aerosol Sci, vol. 29, no. 5, pp. 553-60, 1998.

[11] K. H. Park, J. Olortegui-Yume, and M.C. Yoon, "A study on droplets and their distribution for minimum quantity lubrication (MQL)", International Journal of Machine Tools \& Manufacture. vol. 50, no. 9, pp. 824-33, 2010.

[12] J. A. Sanchez, I. Pombo, R. Alberdi, B. Izquierdo, N. Ortega, S. Plaza, and J. Martinez-Toledano, "Machining evaluation of a hybrid MQL-CO2 grinding technology", Journal of Cleaner Production, vol. 18, no. 18, pp. 1840-1849, 2010.

[13] U. Baheti, C. Guo, and S. Malkin, "Environmentally conscious cooling and lubrication for grinding", Proceedings of the International Seminar on Improving Machine Tool Performance vol. 2, pp. 643-654, 1998.

[14] L.M. Barczak, A.D.L. Batako, and M.N. Morgan, "A study of plane surface grinding under minimum quantity lubrication (MQL) conditions", International Journal of Machine Tools \& Manufacture, vol. 50, no. 11, pp. 977-985, 2010.

[15] D.U. Braga, A.E. Diniz, G.W.A. Miranda, and N.L. Coppini, "Using a minimum quantity of lubricant (MQL) and a diamond coated tool in the drilling of aluminum-silicon alloys", Journal of Materials Processing Technology, vol. 122, no. 1, pp. 127-138, 2002.

[16] J. P. Davim, P.S. Sreejith, R. Gomes, and C. Peixoto, "Experimental studies on drilling of aluminum (AA1050) under dry, minimum quantity of lubricant, and flood-lubricated conditions", Engineering Manufacture, vol. 20, no. 10, pp. 1605$1611,2006$.

[17] N.R. Dhar, M.T. Ahmed, and S. Islam, "An experimental investigation on effect of minimum quantity lubrication in machining AISI 1040 steel", International Journal of Machine Tools and Manufacture, vol. 47, no. 5, pp. 748-753, 2007.

[18] N.R. Dhar, M.W. Islam, S. Islam, and M.A.H. Mithu, "The influence of minimum quantity of lubrication (MQL) on cutting temperature, chip and dimensional accuracy in turning AISI-1040 steel”, Journal of Materials Processing Technology, vol. 71, no. 1, pp. 93-99, 2006

[19] A. Filipovic, and D.A. Stephenson, "Minimum quantity lubrication applications in automotive power-train machining", Machining Science and Technology, vol. 10, no. 1, pp. 3-22, 2006.

[20] K. Weinert, I. Inasaki, J. W. Sutherl, and T. Wakabayashi, "Dry machining and minimum quantity lubrication", Annals of the CIRP, vol. 53, no. 2, pp. 323-349, 2004.

[21] M. J. Hadad, T. Tawakoli, M. H. Sadeghi, and B. Sadeghi, "Temperature and energy partition in minimum quantity lubrication-MQL grinding process", International Journal of Machine Tools and Manufacture, vol. 54, no. 3-4, pp.10-17, 2012.

[22] M. H. Sadeghi, M. J. Hadad, T. Tawakoli, A. Vesali, and M. Emami, "An investigation on surface grinding of AISI 4140 hardened steel using minimum quantity lubrication-MQL technique", International Journal of Material Forming, vol. 3, no. 4, pp. 241-251, 2010.

[23] L. R. Silva, E. C. Bianchi, R. Y. Fusse, R. E. Cataie, T. V. França, and P. R. Aguiar, "Analysis of surface integrity for minimum quantity lubricant-MQL in grinding", International Journal of Machine Tools and Manufacture, vol. 47, no. 2, pp. 412-418, 2007.

[24] T. Tawakoli, M. J. Hadad, A. Daneshi, M. H. Sadeghi, and B. Sadeghi, "Study on the effects of abrasive and coolant-lubricant types on minimum quantity lubrication-MQL grinding", Advanced Materials Research, vol. 25, no 4, pp. 31-237, 2011.
[25] L. M. Barczak, A. D. L. Batako, and M. N. Morgan, "A study of plane surface grinding under minimum quantity lubrication (MQL) conditions", International Journal of Machine Tools and Manufacture, vol. 50, no. 1, pp. 977-985, 2010.

[26] L. M. Barczak, and A. D. Batako, "Application of minimum quantity lubrication in grinding", Materials and Manufacturing Processes, vol. 27, no. 4, pp. 406-411, 2012.

[27] L. Barczak, "Application of Minimum Quantity Lubrication (MQL) in plane surface grinding", Ph.D. thesis. UK: Liverpool John Moores University 2010.

[28] A. L. Wang, Y. Q. Wei, X. J. Zhu, J. Y. Wang, and X. L.Wu, "Grinding performances of the machining fluids of oils on water", Chinese Journal of Mechanical Engineering, vol. 41, no. 1, pp. 208-211, 2005.

[29] B. Shen, A. P. Malshe, P. Kalita, and A. J. Shih, "Performance of novel MoS2 nanoparticles based grinding fluids in minimum quantity lubrication grinding", Transactions of NAMRI/SME, vol. 6, no. 3, pp. 357-364, 2008.

[30] B. Shen, A. J. Shih, and S. C. Tung, "Application of nanofluids in minimum quantity lubrication grinding", Tribology Transactions, vol. 51, no. 6, pp. 730-737, 2008.

[31] M. Alberts, K. Kalaitzidou, and S. Melkote, "An investigation of graphite nanoplatelets as lubricant in grinding", International Journal of Machine Tools and Manufacture, vol. 49, no. 12, pp. 966-970, 2009.

[32] S. Shaji, and V. Radhakrishnan, "Investigations on the application of solid lubricants in grinding", Proceedings of the Institution of Mechanical Engineers, Part B: Journal of Engineering Manufacture, vol. 216, no.10, pp. 1325-1343, 2002.

[33] C. H. Li, Y. L. Hou, S. C. Xiu, and G. Q. Cai, "Application of lubrication theory to near-dry-green grinding-feasibility analysis", Advanced Material Research. vol. 135, no. 4, pp. 44-46, 2008.

[34] C. H. Li, C. Du, G. Y. Liu, and Y. Zhou, "Performance evaluation of minimum quantity cooling lubrication using $\mathrm{CBN}$ grinding wheel", Advanced Materials Research, vol. 97, no. 4, pp. 827-1831, 2010.

[35] C. H. Li, Z. L. Han, Q. Zhang, and S. Wang, "Modeling and experimental investigation of pressure field in the grinding zone with nanoparticle jet of MQL", Advances in Mechanical Engineering, vol. 2013, no. 1, pp. 1-10, 2013.

[36] C. H. Li, J. Y. Li, S. Wang, and Q. Zhang, "Modeling and numerical simulation of the grinding temperature field with nanoparticle jet of MQL", Advances in Mechanical Engineering, vol. 2013, no. 2, pp. 1-9, 2013.

[37] C. Mao, X. J. Tang, H. F. Zou, X. M. Huang, and Z. X. Zhou, "Investigation of grinding characteristic using nanofluid minimum quantity lubrication", International Journal of Precision Engineering and Manufacturing, vol. 13, no. 10, pp. 1745-1752, 2012.

[38] C. H. Li, S. Wang, Q. Zhang, and D. Z. Jia, "Evaluation of minimum quantity lubrication grinding with nano-particles and recent related patents", Recent Patents on Nanotechnology, vol. 7, no. 2, pp. 167-181, 2013.

[39] P. Kalita, A. P. Malshe, S. A. Kumar, V.G. Yoganath; and T. Gurumurthy, "Study of specific energy and friction coefficient in minimum quantity lubrication grinding using oil-based nanolubricants", Journal of Manufacturing Processes, vol. 14, no. 2, pp. 160-166, 2012.

[40] L. D. Gu, G. Y. Meng and C. H. Li, "Selections and calculations of fluid supply parameters in near dry grinding for green manufacturing", Coal Mine Machinery, vol. 29, no. 12, pp. 94-94, 2008.

[41] S. S. Shang, G. Y. Meng and C. H. Li, "Analysis and optimization of gringding parameters for surface grinding using MQL", Machinery Design \& Manufacture, vol. 26, no. 6, pp. 90-92, 2009.

[42] Z. R. Liu, "The Research of Heat Transfer Theory by Nanofluids Jet Lubrication and the Evaluation of the Surface Integrity in Grinding”, MSc Thesis, Qingdao Technological University, Qingdao, CA, China, 2010.

[43] Z. L. Han, "The Simulation and Experimental Investigation in Field of MQL Grinding Zone with Nanoparticles Jet", MSc Thesis, Qingdao Technological University, Qingdao, CA, China, 2012.

[44] J. Y. Li, "The Simulation and Experimental Investigation on Grinding Heat by Nanofluids Jet Lubrication", MSc Thesis, Qingdao Technological University, Qingdao, CA, China, 2012. 
[45] Q. Zhang, C. H. Li and S. Wang, "Analysis of cooling characteristic for minimum quantity lubrication with nanoparticles", Manufacturing Technology \& Machine Tool, vol. 32, no. 3, pp. 2013, 91-96, 2013.

[46] S. Wang, C. H. Li and Q. Zhang, "Evaluation of grinding performance in minimum quantity lubrication with nanoparticles. Manufacturing Technology \& Machine Tool, vol. 32, no. 2, pp. 8689, 2013.

[47] Z. L. Han and C. H. Li, "Theoretical modeling and simulation of airflow field near grinding", International Journal of Control and Automation, vol. 6, no. 4, pp. 145-155, 2013.

[48] S. Wang, C. H. Li, and Y. C. Ding, "Investigation into speed and temperature field of metal drop in high-melting metal arc spraying", International Journal of Control and Automation, vol. 5, no. 3, pp. 237-248, 2012.

[49] C. H. Li, Y. L. Hou, Y. C. Ding, and G. Q. Cai, "Feasibility investigations on compound process: a novel fabrication method for finishing with grinding wheel as restraint", International Journal of Computational Materials Science and Surface Engineering, vol. 4, no. 1, pp. 55-68, 2011.

[50] C. H. Li, Y. L. Hou, Z. R. Liu, and Y. C. Ding, "Investigation into temperature field of nano-zirconia ceramics precision grinding", International Journal of Abrasive Technology, vol. 4, no. 1, pp. 7789, 2011.
[51] C. H. Li, Z. R. Liu, Y. L. Hou, and Y.C. Ding, "Critical conditions for brittle-ductile removal transition in nano- $\mathrm{ZrO}_{2}$ dental ceramic grinding", International Journal of Machining and Machinability of Materials, vol. 11, no. 4, pp. 342-352, 2012.

[52] D. Z. Jia, C. H. Li, and R. Z. Li, "Modeling and Experimental investigation of the flow velocity field in the grinding zone", International Journal of Control and Automation, vol. 7, no. 2 pp. 405-416, 2014

[53] D. K. Zhang, C. H. Li, D. Z. Jia and Y. B. Zhang, "Investigation into engineering ceramics grinding mechanism and the influential factors of the grinding force", International Journal of Control and Automation, vol. 7, no. 4, pp. 19-34, 2014

[54] D. K. Zhang, C. H. Li, , Y. B. Zhang, , D. Z. Jia, and X. W. Zhang, "Experimental research on the energy ratio coefficient and specificgrinding energy in nanoparticle jet MQL grinding", International Journal of Advanced Manufacturing Technology, vol.78, no. 5-8, pp. 1275-1288, 2015.

[55] D. K. Zhang, C. H. Li, Y. B. Zhang, , D. Z. Jia, , and X. W. Zhang, "Specific grinding energy and surface roughness of nanoparticle jetminimum quantity lubrication in grinding", Chinese Journal of Aeronautics, vol.28, no.2, pp. 570-581, 2015.

[56] D. K. Zhang, C. H. Li, D. Z. Jia, D. Z. Wang, and S. H. Yali, "Experimental evaluation on tribological properties of nanoparticle jetMQL grinding", International Journal of Surface Science and Engineering, vol.9, no.2-3, pp.159-175, 2015.

(C) Zhang et al.; Licensee Bentham Open.

This is an open access article licensed under the terms of the Creative Commons Attribution Non-Commercial License (http://creativecommons.org/licenses/by-nc/3.0/) which permits unrestricted, non-commercial use, distribution and reproduction in any medium, provided the work is properly cited. 